\title{
Theoretical Study on Combustion of Injected Pulverized Coal in the Blast Furnace Blowpipe Zone*
}

\author{
By Shin-ichiro NOMURA $A^{* *}$ and M.J. MCCARTHY***
}

\section{Synopsis}

Pulverized coal is being used increasingly as a blast furnace injectant. It is injected into a blowpipe zone where spontaneous ignition and combustion occur by mixing with the hot blast.

A theoretical study is made on the ignition and combustion of injected coal particles in the blowpipe zone. The theory uses a simple combustion model in which diffusion of gaseous oxygen is dominant for the combustion rate. The derived results show the effects of coal properties and blast and injection conditions on the degree of burn out and the blast gas temperature at the tuyere nose. These results are compared qualitatively with reported experiments and reasonable agreement is obtained.

In spite of some severe assumptions used in the theory for simplicity, the present objective is satisfied, which is to provide preliminary information for optimization of the injection conditions.

\section{Introduction}

In order to reduce coke consumption in blast furnace operations, auxiliary fuel such as oil or natural gas is injected into the blast furnace. However, since the oil crisis, the utilization of coal has become very important and pulverized coal is used increasingly to replace oil as a blast furnace injectant.

Like oil and natural gas injection, pulverized coal is injected into a blowpipe immediately upstream of the tuyere nose followed by the coke combustion or 'raceway' zone. Through the injection practices of pulverized coal in various countries, some problems have been experienced. ${ }^{1)}$ These problems include handling and dispensing the powdered coal, the lower combustibility of pulverized coal relative to oil and natural gas and the ash deposition in the tuyeres and its behaviour within the blast furnace.

Some solutions for these problems have been demonstrated by various researchers. For instance, coal handling processes with dense bulk transportation lines are being developed or improved in order to achieve a stable injection of fine coal at a desired injection rate (Wakuri et al., ${ }^{2)}$ Shinozaki et al., ${ }^{3)}$ Reintjes and Tamura, ${ }^{4}$ Hetherington. ${ }^{5)}$ From the Weirton and Bruceton furnace practices, Ostrowski ${ }^{11}$ has recommended the use of coals with low ash content and ash of high ash fusibility (low ash fusion temperature) to minimize build-ups of frozen ash and slag mixtures near tuyeres or blowpipes leading to tuyere or blowpipe failure.

The combustion rate of pulverized coal is relatively low compared to that of oil, which is also a very important factor to be taken into account in the design of coal injection systems. If injected coal particles remain unburnt in the raceway region, they could possibly become lodged in the interstices of the coke bed, decrease the bed permeability and produce detrimental effects on the hot gas flow distribution in the burden. According to Ostrowski, ${ }^{1)}$ changes in gas flow distribution would form accretions with liquid metal on the furnace walls and cause severe slips. Therefore, for good furnace operation with pulverized coal injection, it is of great importance that all the injected coal particles are burnt out before reaching the raceway boundary.

The present work is aimed at developing a simple model for examining the ignition and combustion of pulverized coal injected into a blast furnace blowpipe region. The complex interactions which occur within the raceway zone are not examined at this stage, since it is the intention of the present work to provide preliminary information on the degree of combustion of injected coal at the tuyere nose as a function of coal properties, blast conditions and injection lance position.

\section{Model for Blowpipe-tuyere Combustion Zone}

Figure 1 shows the diagram of pulverized coal injection into a one-dimensional ( $X$-direction) adiabatic blowpipe. For simplicity, the coal particles are assumed to be mono-sized spheres and dispersed uniformly along the cross section of the blowpipe.

As the injected coal particles encounter the blast gas at a temperature greater than $1000 \mathrm{~K}$, they are warmed up, ignited and burnt during passage through the blowpipe.

The present blowpipe model comprises two zones along the $X$-direction, one is the warm-up zone and the other is the burning zone. The warm-up zone is defined as the region between the injection point and the point at which the temperature of particles reaches the ignition temperature, $T_{i g}$. The region further downstream where the particles burn is

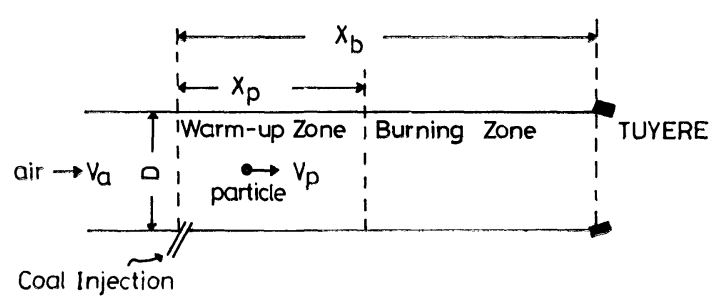

Fig. 1. Model of blowpipe-tuyere combustion zone.

* Based on the paper presented to the 111th ISIJ Meeting, April 1986, S76, at the University of Tokyo in Tokyo. Manuscript received on January 27, 1986; accepted in the final form on June 13, 1986. (C) 1986 ISIJ

** Department of Chemical Process Engineering, Hokkaido University, Nishi 8-chome, Kita 13-jo, Kita-ku, Sapporo 060.

*** Gentral Research Laboratories, The Broken Hill Proprietary Co. Ltd., Shortland, NSW 2287, Australia. 
denoted as the burning zone.

\section{Theoretical}

Coal particles are injected into a blowpipe at the mass rate of $F$. Then, the number injection rate of coal particles per unit cross sectional area of the blowpipe, $\mathcal{N}$, can be represented by,

$$
\mathcal{N}=4 F /\left(\pi D^{2} M_{0}\right)
$$

where, $\quad M_{0}=(\pi / 6) D_{p 0}^{3} \rho_{s}$

$D$ : the diameter of pipe

$D_{p 0}, \rho_{s}$ : the diameter and density of particles, respectively.

The velocity of particles, $V_{p}$ at a distance $X$ is defined by,

$$
V_{p}=d X / d t
$$

The relative velocity, $U$ is,

$$
U=V_{a}-V_{p}
$$

where, $V_{a}$ : the blast gas velocity.

$U$ can be obtained from the following differential equation with respect to the drag force on a particle.

$$
M_{e} d U / d t=-C_{f} A_{s}\left(\rho U^{2} / 2\right)
$$

where, $M_{e}=(\pi / 6) D_{p e}^{3} \rho_{s}=M_{0} C_{\text {ash }}+M(t)$

$$
A_{s}=(\pi / 4) D_{p e}^{2}
$$

$C_{\text {ash }}$ is the mass fraction of ash in the original coal, $\rho$ is the air density, and $C_{f}$ is the resistance coefficient given by,

$$
\begin{array}{ll}
C_{f}=24 / R e & \text { if } R e=D_{p e} U \rho / \mu<2 \\
C_{f}=10 / R e^{0.5} & \text { if } 2<R e<5 \times 10^{2} \\
C_{f}=0.44 & \text { if } 5 \times 10^{2}<R e<2 \times 10^{5}
\end{array}
$$

where, Re: Reynolds number

$\mu$ : the viscosity of gas.

$M_{e}$ in Eq. (4) is the mass of a particle at time $t$ following the injection at $t=0$, which comprises the mass of ash, $M_{0} C_{\text {ash }}$ and that of unburnt fuel of the particle at time $t, M(t) . \quad D_{p e}$ and $A_{s}$ in Eq. (4) are the apparent diameter and projected surface area of the particle at time $t$ where the particle is assumed to be non-porous.

\section{Length of the Warm-up Zone}

The following main assumptions are made in the theoretical derivation in the warm-up zone;

(1) There is no temperature distribution inside the coal particles.

(2) There is no pressure gradient in the warmup zone.

(3) Of the radiation from hot gas and the inside wall of blowpipe, only that from the inside wall is taken into account for the temperature rise of the particles since the main components of the gas $\left(\mathrm{N}_{2}\right.$ and $\mathrm{O}_{2}$ ) are ineffective for radiation. The rate of radiant heat from the inside wall to a particle, $Q_{r}$ can be conveniently represented by,

$$
Q_{r}=\pi D_{p 0}^{2} F_{p} A_{p} E_{w} \sigma T_{0}^{4}
$$

where, $A_{p}$ : the absorptivity of particle

$E_{w}:$ the emissivity of the wall

$\sigma:$ the Stefan-Boltzmann constant

$F_{p}$ : the modified view factor (see Appendix A).

(4) There is no mass loss of solid particles in the warm-up zone so that $D_{p e}$ is equal to $\mathrm{D}_{p 0}$ in Eqs. (4) and (5).

(5) The effect of volatile matter on the temperature rise of particles is very small compared with that of convection (see Appendix $B$ ).

(6) The gas temperature, $T_{g}$ is constant (see Appendix $B$ ) so that the gas velocity does not vary.

(7) In Eq. (5) the Allen region, $C_{f}=10 / R e^{0.5}$, may be reasonably accepted (see Appendix $B$ ).

Using assumptions (4), (6) and (7), Eq. (4) can be solved and the particle velocity, $V_{p}$ is given by,

$$
\begin{aligned}
& V_{p}=V_{a 0}-\left\{\left(V_{a 0}-V_{p 0}\right)^{-0.5}+0.5 B_{1} t\right\}^{-2} \\
& B_{1}=7.5\left(\rho_{0} \mu\right)^{0.5} /\left(\rho_{s} D_{p 0}^{1.5}\right) \ldots \ldots \ldots \ldots \ldots \ldots \ldots \ldots \ldots \ldots
\end{aligned}
$$

where, $V_{a 0}, V_{p 0}$ : the velocities of blast gas and particles at $X=0$, respectively.

Integration of $\mathrm{Eq}$. (2) using $\mathrm{Eq}$. (7) gives the position of particles at time $t$ in the blowpipe, injected at $t=0$, as follows;

$$
\begin{aligned}
X= & V_{a 0} t-\left(2 / B_{1}\right)\left[\left(V_{a 0}-V_{p 0}\right)^{0.5}\right. \\
& \left.-\left\{\left(V_{a 0}-V_{p 0}\right)^{-0.5}+0.5 B_{1} t\right\}^{-1}\right]
\end{aligned}
$$

Consider a single particle travelling from $X$ to $X+d X$ in a small period of time, $d t$. Using assumptions (3) and (5), a heat balance around the particle becomes,

$$
\begin{aligned}
\frac{d T_{s}}{d t} & =A_{1}\left\{h\left(\mathcal{T}_{g}-\mathcal{T}_{s}\right)+G_{m}\right\} \\
D_{p 0} h / K_{c} & =2+0.6 \operatorname{Re}^{1 / 2} \operatorname{Pr}^{1 / 3} \\
A_{1} & =6 /\left(D_{p 0} \rho_{s} C_{p s}\right) \\
G_{m} & =F_{p} A_{p} E_{w} \sigma T_{0}^{4} \quad \ldots \ldots \ldots
\end{aligned}
$$

where, $C_{p s}$ : the specific heat of solid

$K_{c}$ : the thermal conductivity of gas

$\operatorname{Pr}$ : the Prantdl number

$h$ : the heat transfer coefficient.

When the particle reaches the boundary of the warmup and burning zones $\left(X=X_{p}\right.$ or $\left.t=t_{1}\right)$, its temperature, $T_{s}$ attains the ignition temperature, $T_{i g}$. From the solution of Eq. (9), the time that the particle reaches the boundary, $t_{1}$ is obtained by,

$$
t_{1}=\frac{1}{A_{1} h} \ln \frac{h\left(T_{s 0}-T_{0}\right)-G_{m}}{h\left(T_{i g}-T_{0}\right)-G_{m}}
$$

where the heat transfer coefficient, $h$ is regarded as constant and is calculated by using $R e$ based on the average relative velocity, $U$ equal to $V_{a 0}-X_{p} / t_{1}$. Substituting the above equation into Eq. (8), the length of the warm-up zone, $X_{p}$ can be calculated as $X\left(t_{1}\right)$.

\section{Length of the Burning Zone}

At the boundary of the warm-up and burning 
zones, the injected coal particles start to burn and heat the surrounding gas. In the burning zone, therefore, the velocity, density and temperature of gas vary in the $X$-direction.

The equations of mass and energy balances at steady state in the gas phase and the ideal gas law can be given as follows;

$$
\begin{aligned}
& \text { (mass) } \\
& -\frac{d\left(\rho V_{a}\right)}{d X}+\frac{\mathcal{N}}{V_{p}}\left\{-\frac{d M(t)}{d t}\right\}=0 \\
& \text { or } \\
& \left(\rho / \rho_{0}\right)\left(V_{a} / V_{a 0}\right)=1+Y(\theta) \\
& -\frac{d}{d X}\left\{\rho V_{a}\left(H G_{q}+0.5 V_{a}^{2}\right)\right\} \\
& +\frac{G_{q} Q_{s} \mathcal{N}}{V_{p}}\left\{-\frac{d M(t)}{d t}\right\}=0 \\
& \{1+Y(\theta)\}\left\{Y_{a}\left(T_{g} / T_{0}\right)+0.5\left(V_{a} / V_{a 0}\right)^{2}\right\} \\
& =Y_{a}+Y_{b} Y(\theta)+0.5
\end{aligned}
$$

where,

$$
\begin{aligned}
& Y(\theta)=\left\{\mathcal{N} M_{0}\left(1-C_{\text {ash }}\right) /\left(\rho_{0} V_{a 0}\right)\right\}\left\{1-M_{d}(\theta)\right\} \\
& Y_{a}=G_{q} G_{p} T_{0} / V_{a 0}^{2} \\
& Y_{b}=G_{q} Q_{s} / V_{a 0}^{2} \\
& M_{d}(\theta)=M(t) /\left\{M_{0}\left(1-C_{\text {ash }}\right)\right\} \\
& \theta\left(=t-t_{1}\right): \text { the time variable indicating the } \\
& \text { burning period } \\
& G_{q} \text { : the conversion factor }\left(G_{q}=1 \mathrm{kgm}^{2} /\right. \\
& \mathrm{Js}^{2} \text { ) }
\end{aligned}
$$

For further simplicity, the following assumptions are introduced;

(8) The pressure is constant (see Appendix $C$ ).

(9) The particle velocity, $V_{p}$ is equal to that of blast gas, $V_{a}$ (see Appendix $C$ ).

Using Eqs. (11) to (13) and assumption (8), $V_{a}$ and $T_{g}$ can be represented as follows:

$$
\begin{aligned}
& V_{a} / V_{a 0}=\left[-Y_{a}+\left\{Y_{a}^{2}+2(1+Y(\theta))\left(Y(\theta) Y_{b}\right.\right.\right. \\
& \left.\left.\left.+Y_{a}+0.5\right)\right\}^{0.5}\right] /\{1+Y(\theta)\} \\
& T_{g} / T_{0}=\left(V_{a} / V_{a 0}\right) /\{1+Y(\theta)\}
\end{aligned}
$$

From assumption (9), the distance, $X$ from the injection lance (the position of particles in the blowpipe at time $\theta$ ) can be obtained by,

$$
X=\int_{0}^{\theta} V_{a} d \theta+X_{p}
$$

Thus, the time, $t_{s}$ or $\theta_{s}\left(=t_{s}-t_{1}\right)$ when the injected particles reach the tuyere nose (the edge of blowpipe) can be evaluated by substituting $X_{b}$ in $X$ in Eq. (16).

\section{Combustion Rate of Coal}

The above equations (14) to (16) include $M_{d}(\theta)$, the dimensionless mass of unburnt fuel of the particle at time $\theta$. For the combustion of a single particle, diffusion of oxygen is assumed to be dominant. Then, the rate of combustion can be represented by, ${ }^{6)}$

$$
M_{0}\left(1-C_{\mathrm{ash}}\right)\left\{-\frac{d M_{d}(\theta)}{d \theta}\right\}=(1 / \alpha) \pi D_{p}^{2} k_{o} C_{g}
$$

where $\alpha$ is the number of moles of oxygen consumed per unit mass of particle burnt and $k_{o}$ is the mass transfer coefficient which is obtained by assuming that the Sherwood number is equal to 2 , that is,

$$
\begin{aligned}
k_{o} & =2 D_{f f} / D_{p} \ldots \ldots \ldots \ldots \ldots \ldots \ldots \\
D_{f f} & =D_{\mathrm{o}}\left(101 / P_{0}\right)\left(T_{g} / 298\right)^{1.75}
\end{aligned}
$$

where, $D_{f f}, D_{0}$ : the diffusion coefficients at $P_{\mathbf{0}}$ and $T_{g}$ and at standard state $(101 \mathrm{kPa}$ and $298 \mathrm{~K}$ ), respectively.

In Eq. (17), $C_{g}$ is the oxygen concentration at $X=X$ (or $\theta=\theta)$ which is obtained by taking a oxygen balance of the blast gas along the $X$-direction in the blowpipe,

$$
\begin{aligned}
& \frac{\pi D^{2}}{4}\left(C_{g 0} V_{a 0}-C_{g} V_{a}\right)=\alpha F\left(1-C_{\mathrm{ash}}\right)\left\{1-M_{d}(\theta)\right\} \\
& \ldots \ldots \ldots \ldots \ldots \ldots \ldots \ldots \ldots \ldots \ldots \ldots \ldots \ldots \ldots \ldots \ldots \ldots \ldots
\end{aligned}
$$

where, $C_{g 0}$ : the oxygen concentration at $X=0$

$C$ : the oxygen content at $X=X$.

Rearranging Eq. (19) gives,

$$
C=\left\{C_{0}-28.8 \times 10^{-3} \alpha Y(\theta)\right\} /\{+Y(\theta)\}
$$

where, $C_{0}$ : the initial oxygen content of the blast gas at $X=0$.

Using Eqs. (18), (20) and (21), Eq. (17) is reduced to,

$$
-\tau_{0} \frac{d M_{d}(\theta)}{d \theta}=\frac{3}{2} M_{d}(\theta)^{1 / 3}\left(\mathcal{T}_{g} / \mathcal{T}_{0}\right)^{0.75}\left(C / C_{0}\right)
$$

where, $\tau_{0}=K_{d_{0}}\left(298 / \mathcal{T}_{0}\right)^{0.75}\left(0.21 / C_{0}\right) D_{p 0}^{2}$

and $\quad K_{d o}=(298 / 101 / 0.21) R \rho_{s}\left(1-C_{\mathrm{ash}}\right) \alpha /\left(8 D_{\mathrm{o}}\right)$

Equation (22) can be solved analytically if the value of $\left(T_{q} / \mathcal{T}_{0}\right)^{0.75}\left(C / C_{0}\right)$ can be regarded as constant, which might be reasonable because the value of $\left(T_{g} / T_{0}\right)$ increases with increasing time $\theta$ whereas $\left(C / C_{0}\right)$ decreases with $\theta$. Assuming the mean values $T_{A}$ and $C_{A}$ for $T_{g}$ and $C$, integration of Eq. (22) becomes,

$$
\begin{aligned}
& M_{d}(\theta)=\left(1-\theta / \tau_{A}\right)^{3 / 2} \\
& \tau_{A}=K_{d A} D_{p 0}^{2} \\
& K_{d A}=K_{d o}\left(298 / T_{A}\right)^{0.75}\left(0.21 / C_{A}\right) \\
& T_{A} / T_{0}=\left\{1+\left(T_{r} / T_{0}\right)\right\} / 2 \\
& C_{A} / C_{0}=\left\{1+\left(C_{r} / C_{0}\right)\right\} / 2
\end{aligned}
$$

where $T_{r}$ and $C_{r}$ are the gas temperature and the oxygen content at the tuyere nose and are obtained by substituting $\theta_{s}$ into $\theta$ in Eqs. (15) and (21), respectively.

Figure 2 shows the validity of the assumption to 


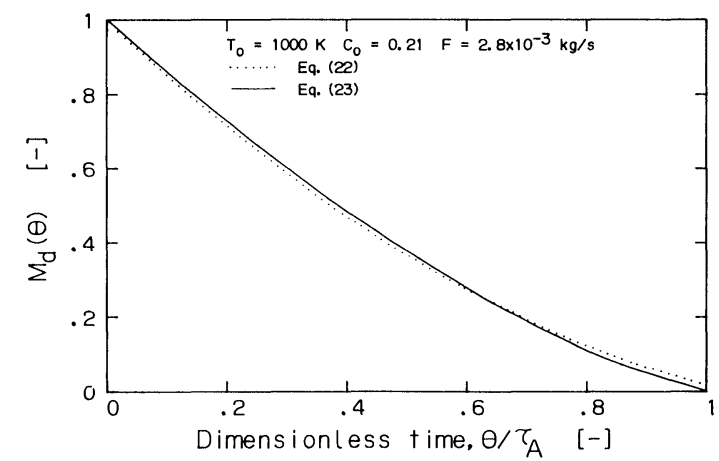

Fig. 2. Fraction of unburnt fuel of a particle in relation to dimensionless burning time.

derive Eq. (23), where the coal injection rate $(2.8 \times$ $10^{-3} \mathrm{~kg} / \mathrm{s}$ ) is about a half the stoichiometric value.

Additionally, $\tau_{A}$ in Eq. (24) is the time required for complete combustion of a particle of a diameter $D_{p 0}$ under the condition of $T_{A}$ and $C_{A}$. Further, the degree of burn-out of particles at $X=X_{b}, C_{d}$, becomes $1-M_{d}\left(\theta_{s}\right)$.

\section{Calculated Results and Discussion}

Two series of experiments of pulverized coal combustion (Burgess et al..$^{7)}$ and McCarthy et al. ${ }^{8)}$ ) are referred to for comparing with the theory. Both used pilot scale blast blowpipe-tuyere combustion systems. The former ${ }^{7}$ tested two different coals (types A and B) and measured the gas temperatures in the blowpipe combustion region in relation to the distance from the injection position (shown in Figs. 3 and 4). The latter ${ }^{8)}$ tested three kinds of medium to high volatile coal (types $\mathrm{C}, \mathrm{D}$ and E). They sampled the burning coal particles with a solid sampling probe and analysed the ash content to evaluate the degree of burn-out. Figure 5 shows a typical example of the results relating the degree of burn-out to the coal injection rate. The characteristics of the coals and the experimental conditions employed by both researchers are given in Tables 1 and 2, respectively.

In the calculation, the ignition temperature, $T_{i g}$ for the coals is assumed to be $1000 \mathrm{~K}$ (see Nomura and Callcott $\left.{ }^{9}\right)$ ). Further, the emissivity of blowpipe wall, $E_{w}$ is assumed to be 0.9 since the effect of $E_{w}$ in the range from 0.5 to 1 is only 2 or $3 \%$ on the value of $X_{p}$ and its value seems to be between 0.7 and 1. ${ }^{10)}$ Other constant values needed for calculation are listed in Table 3.

Since no specific values of $K_{d_{0}}$, the burning constant, are available for these coals, they are estimated from the experimental data. Then, using these values of $K_{d o}$, the sensitivity of the theory is tested and compared with the trends obtained in the experiments.

Firstly, for coals $\mathrm{A}$ and $\mathrm{B}$, the values of $\kappa_{d o}$ have been calculated which give a best fit to the measured gas temperatures for $F=1.4 \times 10^{-3} \mathrm{~kg} / \mathrm{s}$ for coal $A$ and for $F=1.1 \times 10^{-3} \mathrm{~kg} / \mathrm{s}$ for coal $B$. These have been $3 \times 10^{7} \mathrm{~s} / \mathrm{m}^{2}$ for both $A$ and $B$. Using the obtained values of $K_{d 0}$, further calculations have been made on

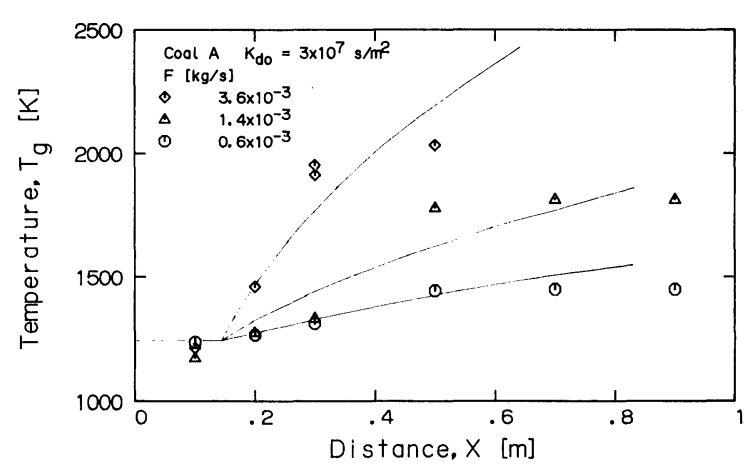

Fig. 3. Blast gas temperature in relation to distance from injection position for coal A.

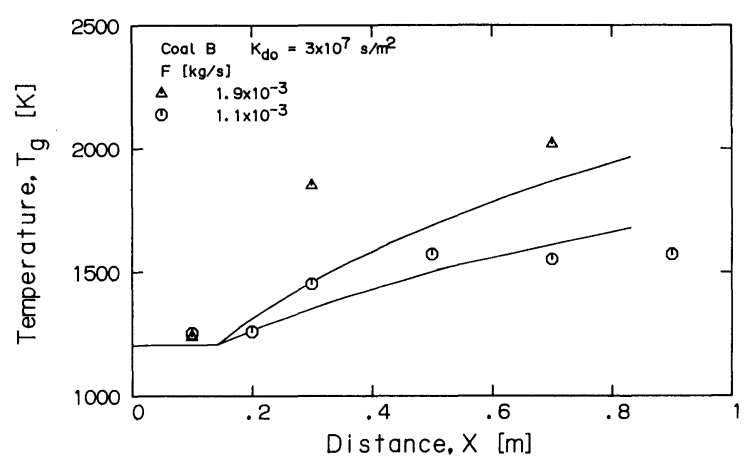

Fig. 4. Blast gas temperature in relation to distance from injection position for coal $\mathrm{B}$.

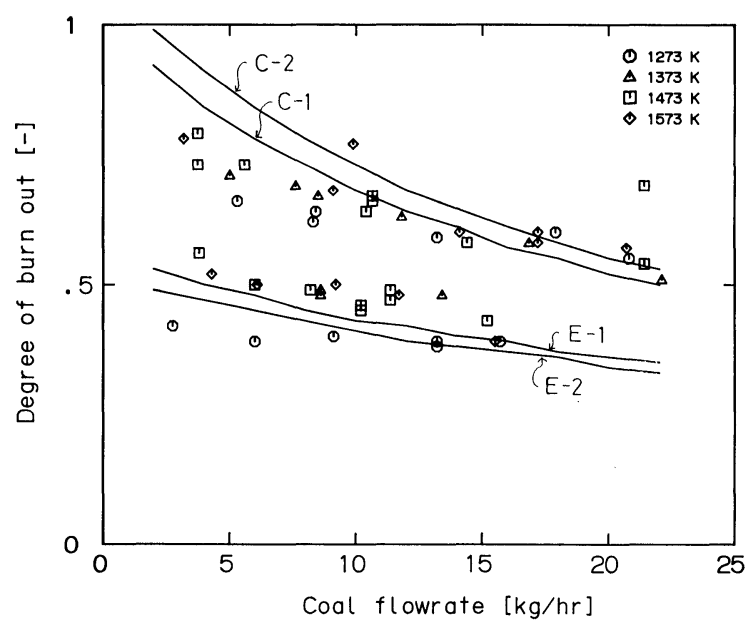

Fig. 5. Degree of burn out in relation to coal injection rate.

the gas temperatures in terms of $X$ at other coal injection rates employed in the test, which are shown as the full lines in the corresponding figures 3 and 4. Judging from comparison with the experiments, the theoretical estimate seems reasonable.

Next, the values of $K_{d \mathrm{o}}$ for coals $C, D$ and $E$ have been re-calculated by substituting data of degree of burnout and the employed experimental condition. ${ }^{8)}$ For each coal the average is adopted as the value of $K_{d_{0}}$. These are $2.15 \times 10^{7} \mathrm{~s} / \mathrm{m}^{2}$ for coal $C, 2.88 \times$ $10^{7} \mathrm{~s} / \mathrm{m}^{2}$ for coal $D$ and $5.14 \times 10^{7} \mathrm{~s} / \mathrm{m}^{2}$ for coal $E$. Using these values and the experimental conditions, the degrees of burnout are calculated and compared 
Table 1. Coal compositions. (wt \%)

\begin{tabular}{|c|c|c|c|c|c|c|}
\hline \multirow{2}{*}{\multicolumn{2}{|c|}{ Component }} & \multicolumn{5}{|c|}{ Coal Type } \\
\hline & & A & B & G & $\mathrm{D}$ & $\mathrm{E}$ \\
\hline \multirow{4}{*}{ 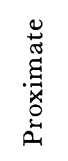 } & Volatile matter & 35.9 & 33.3 & 36.0 & 33.9 & 17.1 \\
\hline & Ash & 4.0 & 10.0 & 3.8 & 12.5 & 9.9 \\
\hline & Moisture & 1.0 & - & 6.2 & 3.1 & 1.7 \\
\hline & Fixed carbon & 59.1 & 56.7 & 54.0 & 50.5 & 71.3 \\
\hline \multirow{5}{*}{ 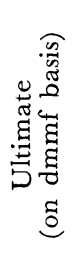 } & G & 79.38 & 75.3 & 80.0 & 77.2 & 80.4 \\
\hline & $\mathrm{H}$ & 5.13 & 4.9 & 4.9 & 5.0 & 4.3 \\
\hline & $\mathrm{O}$ & 8.41 & 7.8 & 12.8 & 15.5 & 12.9 \\
\hline & $\mathrm{S}$ & 0.38 & 0.3 & 0.34 & 0.43 & 0.61 \\
\hline & $\begin{array}{l}\text { Heat of } \\
\text { combustion } \\
Q_{s}\left[\times 10^{6} \mathrm{~J} / \mathrm{kg}\right]\end{array}$ & 31.6 & 29.2 & 31.6 & 30.3 & 30.8 \\
\hline
\end{tabular}

Table 2. Experimental conditions for coal combustion experiments.

\begin{tabular}{l|cccc}
\hline \multirow{2}{*}{ Coal } & \multicolumn{4}{|c}{ Coal Type } \\
\cline { 2 - 5 } & $\begin{array}{c}\text { Blast temp. } \\
(\mathrm{K})\end{array}$ & $\begin{array}{c}\text { Blast } \\
\text { flow } \\
\left(\times 10^{-3}\right. \\
\left.\mathrm{m}^{3} / \mathrm{s}\right)\end{array}$ & $\begin{array}{c}\text { Blowpipe } \\
\text { diameter } \\
(\mathrm{m})\end{array}$ & $\begin{array}{c}\text { Mean } \\
\text { particle } \\
\text { diameter } \\
\left(\times 10^{-6} \mathrm{~m}\right)\end{array}$ \\
\hline A & 1243 & 32.1 & 0.05 & 40.0 \\
B & 1203 & 32.1 & 0.05 & 37.0 \\
C-1 & 1273,1373 & 42.9 & 0.07 & 48.5 \\
C-2 & 1473,1573 & 42.9 & 0.07 & 46.9 \\
D-1 & 1273 & 42.9 & 0.07 & 43.0 \\
D-2 & 1373 & 42.9 & 0.07 & 45.0 \\
E-1 & 1373 & 42.9 & 0.07 & 42.9 \\
E-2 & 1473,1573 & 42.9 & 0.07 & 44.3 \\
\hline
\end{tabular}

Table 3. Gonstant values for calculation.

$\mu^{\ell}=3.4328 \times 10^{-7} T_{A}^{0.6996} \mathrm{~kg} / \mathrm{ms}$

$C_{p}=\left(0.9526 \times 10^{3}+2.1458 \times 10^{-1} T_{A}-3.1206 \times 10^{-5} T_{A}^{2}\right) \mathrm{J} / \mathrm{kgK}$

$\kappa_{e}=\mu\left(C_{p}+0.3603\right) \mathrm{J} / \mathrm{mKs}$

$\rho_{s}=1200 \mathrm{~kg} / \mathrm{m}^{3} \quad C_{p s}=1.463 \times 10^{3} \mathrm{~J} / \mathrm{kgK}$

$A_{p}=E_{p}=0.8$

$E_{w}=0.9$

$\sigma=5.669 \times 10^{-8} \mathrm{~J} / \mathrm{m}^{2} \mathrm{~K}^{4} \mathrm{~s}$

$Q_{v}=5.015 \times 10^{7} \mathrm{~J} / \mathrm{kg}$

$X_{i}=0.5 \mathrm{~m} \quad T_{s 0}=298 \mathrm{~K}$

$T_{i g}=1000 \mathrm{~K}$

$V_{p 0}=13 \mathrm{~m} / \mathrm{s}$ (from Ref. 7))

Assume coal as $\mathrm{C}_{m 1} \mathrm{H}_{m 2} \mathrm{O}_{m 3}$

$\mathrm{C}_{m 1} \mathrm{H}_{m 2} \mathrm{O}_{m 3}+M_{p} \alpha \mathrm{O}_{2} \longrightarrow m_{1} \mathrm{CO}_{2}+0.5 m_{2} \mathrm{H}_{2} \mathrm{O}$

$M_{p}=12 m_{1}+m_{2}+16 m_{3}$

$\alpha=\left(m_{1}+m_{2} / 4-m_{3} / 2\right) / M_{p}$

with the experimental values in Fig. 6. Although some dispersion is observed, the trend of the plots seems to be along the full line with unity slope.

In Fig. 5, the experiment indicates the degree of burnout decreases with increasing coal injection rate, $F$. The theory shows the same trend which is depicted by the full lines. The reason for this trend is explained by using Eq. (24) and Fig. 7. The gas temperature, $T_{A}$ increases with increasing $F$, which enhances the combustion rate or the degree of burn-

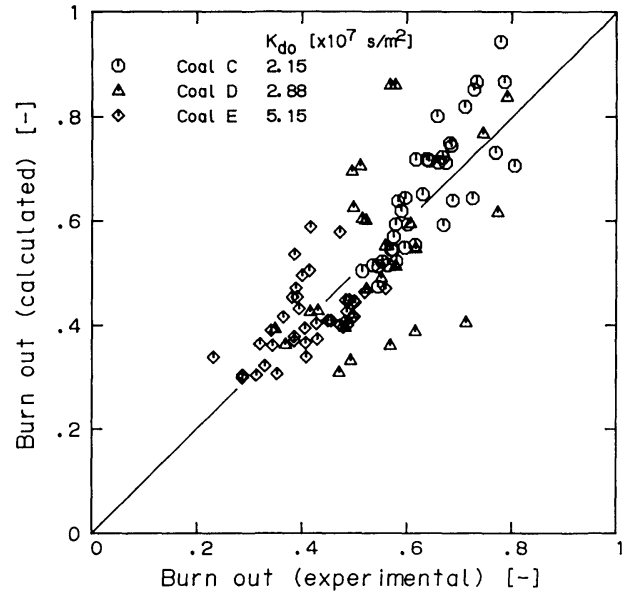

Fig. 6. Comparison of calculated degree of burn out with experimental one.

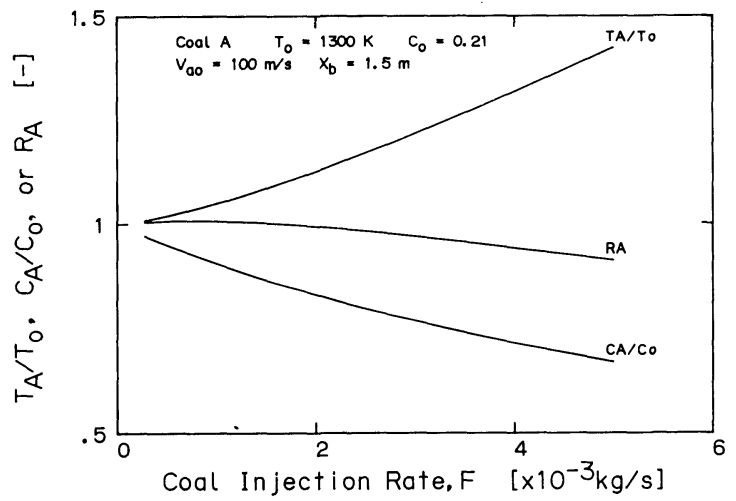

Fig. 7. Effect of coal injection rate on $T_{A}, C_{A}$, and $R_{A}$.

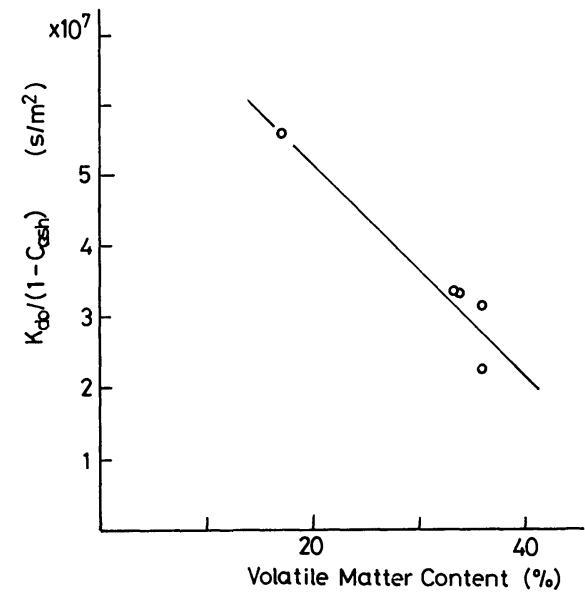

Fig. 8. Relation between $K_{d \mathrm{o}} /\left(1-C_{\mathrm{ash}}\right)$ and volatile matter content.

out. On the other hand, the oxygen content, $C_{A}$ in the blast gas decreases for greater $F$, which reduces the combustion rate. The effect of oxygen content on $K_{d}$ is greater than that of blast gas temperature, which is shown in Fig. 7 by the line of $R_{A}$, the ratio of $K_{d}$ at $T_{0}$ and $C_{0}$ to that at $T_{A}$ and $C_{A}$. This causes a slightly decreasing trend of the degree of burnout with increasing coal injection rate.

Figure 8 shows the relationship between the calcu- 
lated $K_{d o}$ value divided by $\left(1-C_{\text {ash }}\right)$ and the volatile matter. Although only a few points have been plotted, a reasonable trend can be seen that $K_{d o}$ decreases (or the combustion rate increases) with increasing volatile matter.

\section{Conclusion}

A theoretical study has been conducted on the combustion of pulverized coal injected into the blast furnace blowpipe region. In this work, a simplified model of the coal combustion has been used in order to derive simple equations. The derived results have explained qualitatively the combustion characteristics occurring in the blowpipe-tuyere region and have been confirmed with reported experiments in reasonable agreement.

The combustion model has used the burning constant, $K_{d_{0}}$ which is a material constant affected by the volatile matter and ash content of the coal. The present work has assumed the values of the burning constant to correspond with reported combustion data. Although the number of the combustion data point is limited, a reasonable correlation has been obtained (Fig. 8) between the burning constant and the volatile matter content. This correlation should be useful in other research areas such as predictions of coal dust explosion phenomena. ${ }^{11)}$

Finally, the objective of the present work is to provide preliminary information for the optimization of blast furnace operations with pulverized coal injection. For this optimization, further research is needed on the raceway zone combustion of injected coals, which should be combined with the present theoretical work.

\section{Nomenclature}

$A$ : projected area defined in Fig. A-1 (b) $\left[\mathrm{m}^{2}\right]$

$A_{1}: \quad 6 /\left(D_{p 0} \rho_{s} C_{p s}\right)\left[\mathrm{m}^{2} \mathrm{~K} / \mathrm{J}\right]$

$A_{2}: \quad \mathcal{N} \pi D_{p 0}^{2} /\left(\rho_{0} V_{a 0} C_{p}\right)\left[\mathrm{m}^{2} \mathrm{~K} / \mathrm{J}\right]$

$A_{i}$ : area of wall inside blowpipe effective for radiation $\left[\mathrm{m}^{2}\right]$

$A_{\mathrm{o}}$ : frequency factor $\left[\mathrm{kg} / \mathrm{m}^{2} \mathrm{~s}\right]$

$A_{p}$ : absorptivity of particle [-]

$A_{s}$ : projected area of a particle $\left[\mathrm{m}^{2}\right]$

$B_{1}: \quad 7.5\left(\rho_{0} \mu\right)^{0.5} /\left(\rho_{s} D_{p 0}^{1.5}\right)\left[\mathrm{m}^{-1}\right]$

$b=\left(T_{r} / \mathcal{T}_{0}\right)-1[-]$

$C$ : mole fraction of oxygen in gas phase at $X=X[-]$

$C_{A}$ : mean value of mole fraction of oxygen in the burning zone [-]

$C_{\mathrm{ash}}$ : mass fraction of ash in original coal $[-]$

$C_{l l}:$ degree of burn-out [-]

$C_{f}:$ resistance coefficient $[-]$

$C_{g}$ : oxygen concentration at $X=X\left[\mathrm{~mol} / \mathrm{m}^{3}\right]$

$C_{g 0}$ : oxygen concentration at $X=0\left[\mathrm{~mol} / \mathrm{m}^{3}\right]$

$C_{0}$ : mole fraction of oxygen in gas phase at $X=0[-]$

$C_{p}: \quad$ specific heat of gas per unit mass at constant pressure $[\mathrm{J} / \mathrm{kgK}]$

$C_{p s}$ : specific heat of particle per unit mass $[\mathrm{J} / \mathrm{kgK}]$

$C_{r}$ : mole fraction of oxygen in blast gas at tuyere nose [-]

$D$ : inside diameter of blowpipe [m]

$D_{f f}$ : diffusion coefficient at temperature, $T_{g}$ and pressure, $P_{0}\left[\mathrm{~m}^{2} / \mathrm{s}\right]$

$D_{0}$ : diffusion coefficient at $298 \mathrm{~K}$ and $101 \mathrm{kPa}$ $\left[\mathrm{m}^{2} / \mathrm{s}\right]$

$D_{p}(t)$ : diameter of unburnt fuel core of particle [m]

$D_{p e}$ : apparent diameter of a burning particle at $t=t[\mathrm{~m}]$

$D_{p 0}$ : initial diameter of particles $[\mathrm{m}]$

$E:$ activation energy $[\mathrm{J} / \mathrm{mol}]$

$E_{w}$ : emissivity of inside wall of blowpipe [-]

$F$ : mass injection rate of pulverized coal $[\mathrm{kg} / \mathrm{s}]$

$F_{p}$ : modified view factor $[-]$

$F_{r}$ : friction force of gas acting on a unit surface area of inside wall $\left[\mathrm{kgm} / \mathrm{s}^{2}\right]$

$f:$ friction coefficient [--]

$G=X / X_{b}[-]$

$G_{c}$ : conversion factor $=980\left[\mathrm{~kg} / \mathrm{mkPas}^{2}\right]$

$G_{i}=X_{i} / X_{b}[-]$

$G_{m}=F_{p} A_{p} E_{w} \sigma \mathcal{T}_{0}^{4}\left[\mathrm{~J} / \mathrm{m}^{2} \mathrm{~s}\right]$

$G_{q}:$ conversion factor $=1\left[\mathrm{kgm}^{2} / \mathrm{Js}^{2}\right]$

$H$ : enthalpy per unit mass of gas $[\mathrm{J} / \mathrm{kg}]$

$h$ : heat transfer coefficient $\left[\mathrm{J} / \mathrm{m}^{2} \mathrm{Ks}\right]$

$K_{c}$ : thermal conductivity of gas $[\mathrm{J} / \mathrm{mK}$ ]

$K_{d A}$ : burning constant at temperature $\mathcal{T}_{A}$ and oxygen content $C_{A}\left[\mathrm{~s} / \mathrm{m}^{2}\right]$

$K_{d_{0}}$ : burning constant at $298 \mathrm{~K}$ and 0.21 oxygen content $\left[\mathrm{s} / \mathrm{m}^{2}\right]$

$k_{o}$ : mass transfer coefficient $[\mathrm{m} / \mathrm{s}]$

$L:$ distance defined in Fig. A-1 (a) $[\mathrm{m}]$

$M(t)$ : mass of unburnt fuel of a particle at time $t$ [kg]

$M_{d}(\theta)=M(t) / M_{0}\left(1-C_{\mathrm{ash}}\right)[-]$

$M_{e}$ : mass of a particle at time $t[\mathrm{~kg}]$

$M_{0}$ : initial mass of a particle [kg]

$M_{p}$ : molecular weight of particle $[\mathrm{kg} / \mathrm{mol}]$

$\mathcal{N}$ : number injection rate of coal particles per unit cross sectional area of blowpipe $\left[\mathrm{m}^{-2}\right.$ $\left.\mathrm{s}^{-1}\right]$

$P:$ pressure of blast gas at $X=X[\mathrm{kPa}]$

$P_{0}$ : pressure of blast gas at $X=0[\mathrm{kPa}]$

Pr: Prandtl number [-]

$Q_{r}$ : rate of heat transferred by radiation $[\mathrm{J} / \mathrm{s}]$

$Q_{s}$ : heat of combustion of particle $[\mathrm{J} / \mathrm{kg}]$

$Q_{v}$ : oxidation heat per unit mass of volatile matter $[\mathrm{J} / \mathrm{kg}]$

$R:$ gas constant $8.288 \times 10^{-3}\left[\mathrm{~m}^{3} \mathrm{kPa} / \mathrm{molK}\right]$ or $8.314[\mathrm{~J} / \mathrm{molK}]$

$R_{A}=\left(T_{A} / T_{0}\right)^{0.75}\left(C_{A} / C_{\mathbf{0}}\right)[-]$

$R_{f}$ : mole flow rate of gaseous oxygen at $X=X_{b}$ $[\mathrm{mol} / \mathrm{s}]$

$R_{1}=2 r / D[-]$

$R e$ : Reynolds number with respect to a particle [-]

$R e^{\prime}$ : Reynolds number with respect to blowpipe [-]

$r$ distance of a particle from the axis of cylinder $[\mathrm{m}]$

$T_{A}$ : mean value of gas temperature in the burning zone $[\mathrm{K}]$ 
$T_{g}:$ temperature of gas at $X=X[\mathrm{~K}]$

$T_{i g}$ : ignition temperature of coal particles $[\mathrm{K}]$

$T_{0}$ : temperature of blast gas at $X=0[\mathrm{~K}]$

$T_{r}$ : temperature of blast gas at tuyere nose $[\mathrm{K}]$

$\mathcal{T}_{s}:$ temperature of particles at $X=X[\mathrm{~K}]$

$\mathcal{T}_{s 0}:$ temperature of particles at $X=0[\mathrm{~K}]$

$T_{w}$ : temperature of wall inside blowpipe $[\mathrm{K}]$

$t:$ time variable $[\mathrm{s}]$

$t_{1}$ : time for injected coal particles to be ignited [s]

$t_{s}$ : time for injected particles to reach tuyere nose $[\mathrm{s}]$

$U=V_{a}-V_{p}[\mathrm{~m} / \mathrm{s}]$

$V:$ volatile matter content [-]

$V_{a}$ : velocity of blast gas at $X=X[\mathrm{~m} / \mathrm{s}]$

$V_{a 0}$ : velocity of blast gas at $X=0[\mathrm{~m} / \mathrm{s}]$

$V_{p}:$ velocity of particles at $X=X[\mathrm{~m} / \mathrm{s}]$

$V_{p 0}$ : velocity of particles at $X=0[\mathrm{~m} / \mathrm{s}]$

$X$ : distance from injection point in blowpipe [m]

$X_{b}$ : distance between injection point and tuyere nose $[\mathrm{m}]$

$X_{i}$ : length of blowpipe upstream of injection point effective to radiation [m]

$X_{p}$ : length of warm-up zone [m]

$Y(\theta)=\mathcal{N} M_{0}\left(1-C_{\mathrm{ash}}\right) /\left(\rho_{0} V_{a 0}\right)\left\{1-M_{d}(\theta)\right\} \quad[-]$

$Y_{a}=G_{q} C_{p} T_{0} / V_{a 0}^{2}[-]$

$Y_{b}=G_{q} Q_{s} / V_{a 0}^{2}[-]$

$Z=\left\{D /\left(2 X_{b}\right)\right\}^{2}[-]$

$Z_{a}=1+R_{1}^{2}-2 R_{1} \cos \phi[-]$

$\alpha$ : moles of oxygen consumed by combustion of unit mass of coal $[\mathrm{mol} / \mathrm{kg}]$

$\beta$ : angle defined in Fig. A-1 [-]

$\theta: t-t_{1}[\mathrm{~s}]$

$\theta_{s}: t_{s}-t_{1}[\mathrm{~s}]$

$\mu:$ gas viscosity $[\mathrm{kg} / \mathrm{ms}]$

$\rho$ : density of blast gas at $X=X\left[\mathrm{~kg} / \mathrm{m}^{3}\right]$

$\rho_{0}$ : density of blast gas at $X=0\left[\mathrm{~kg} / \mathrm{m}^{3}\right]$

$\rho_{s}$ : density of particles $\left[\mathrm{kg} / \mathrm{m}^{3}\right]$

$\sigma$ : Stefan-Boltzmann constant $\left[\mathrm{J} / \mathrm{m}^{2} \mathrm{~K}^{4} \mathrm{~s}\right]$

$\tau_{A}$ : time required for complete combustion of a particle under the conditions of $T_{g}=T_{A}$ and $C=C_{A}[\mathrm{~s}]$

$\tau_{0}$ : time required for complete combustion of a particle under the conditions of $T_{g}=T_{0}$ and $C=C_{0}[\mathrm{~s}]$

$\phi:$ angle defined in Fig. A-1 (a) [-]

\section{REFERENCES}

1) E.J. Ostrowski: Ironmaking Steelmaking, 10 (1983), 215.

2) S. Wakuri, S. Mochizuki, M. Baba, J. Misawa and K. Anan: Trans. ISIJ, 24 (1984), 622.

3) Y. Shinozaki, H. Marushima, M. Yasuno, R. Takabe, T. Iwamura, T. Moriyama, S. Fujii and K. Achiba: Tetsu-toHagané, 68 (1982), S760; Trans. ISIJ, 23 (1983), B77.

4) H. Reintjes and S. Tamura: Iron Steel Eng., (1983), Feb., 33.

5) T. C. Hetherington: BHP Internal Report, Rept. No. CRL/R/30/83 (Nov. 1983), BHP Central Research Laboratories, Australia.

6) R. H. Essenhigh and I. Fells: Disc. Farad. Soc., 30 (1960), 208.

7) J. M. Burgess, A. S. Jamaluddin, M.J. McCarthy, J. G.
Mathieson, S. Nomura, J. S. Truelove and T. F. Wall: Joint Symposium of ISIJ and AIMM, ISIJ, Tokyo, (1983), 129.

8) M. J. McCarthy, J. G. Mathieson, S. Nomura and H. Rogers: Proc. Int'l Conf. Coal Science, Pergamon Press, Sydney, (1985), 423.

9) S. Nomura and T. G. Callcott: Powder Technology, 45 (1986), 145.

10) Chemical Engineering Handbook, 4th ed. (in Japanese), ed. by Soc. Chem. Eng., Japan, Maruzen Press, Tokyo, (1978), 330

11) S. Nomura, M. Torimoto and T. Tanaka: I \& EC Proc. Des. Dev., 23 (1984), 420.

12) H. Kobayashi: Ph.D. Thesis at Massachusetts Institute of Technology, USA, (June, 1976).

\section{Appendix $A$}

Figure A-1 shows the geometrical relation for radiation between the inside wall of pipe with a diameter $D$ and a particle of a diameter $D_{p 0}$ placed in the pipe at $X=0$. The radiant heat, $d Q_{r}$ transferred from a small area, $d A_{i}$ of the inside wall of the pipe to the particle can be represented by the following equations.

$$
\begin{aligned}
& d Q_{r}=A_{p} E_{w} \sigma T_{w}^{4}(A / \pi) d A_{i} \\
& A=\frac{\pi D_{p 0}^{2} \sin \beta}{4 L^{2}}, \sin \beta=\frac{D / 2-r \cos \psi}{L}
\end{aligned}
$$

where, $\mathcal{T}_{w}$ : the temperature of the wall at $X=X$

$A$ : the projected area as shown in Fig. A$1(b)$.

For simplicity, it is assumed that $\mathcal{T}_{w}$ is equal to that of the adjacent gas and that the gas temperature is constant for $X<0$ and has a linear relationship with the distance, $X$ for $X>0$, that is,
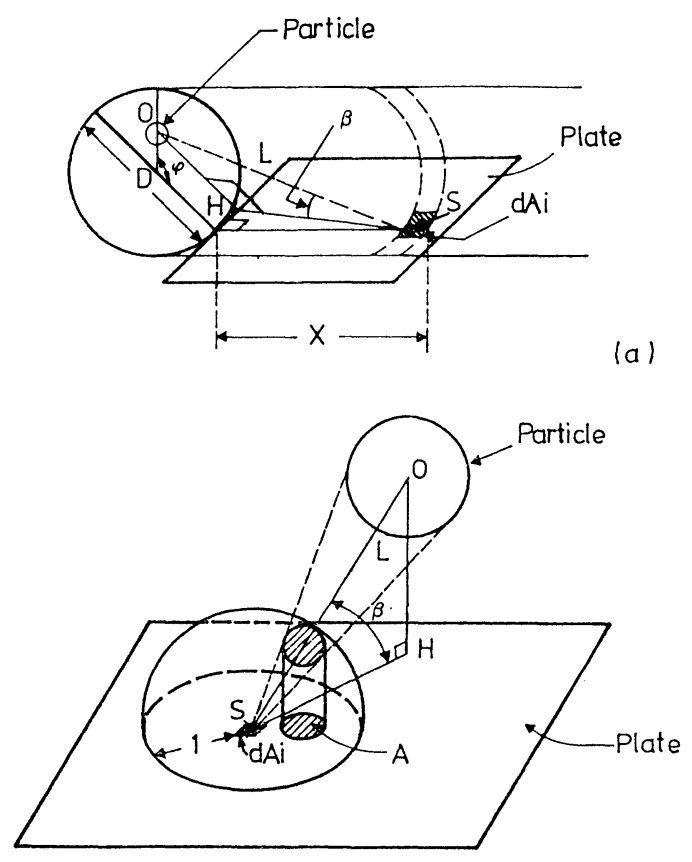

$$
\begin{aligned}
\mathrm{OH} & =\frac{\mathrm{D}}{2}-r \cos \varphi \\
\mathrm{SH} & =\sqrt{\mathrm{X}^{2}+r^{2} \sin ^{2} \varphi}
\end{aligned}
$$

Fig. A-1. View factor geometry. 


$$
\begin{aligned}
& T_{w}=T_{0} \\
& T_{w}=\left(T_{r}-T_{0}\right)\left(X / X_{b}\right)+T_{0}
\end{aligned}
$$

where, $T_{r}$ : the gas temperature at the tuyere nose $\left(X=X_{b}\right)$.

Integration of Eq. (A-1) gives the total radiant heart, $Q_{r}$ from the inside wall to the particle as follows.

$$
Q_{r}=\pi D_{p 0}^{2} A_{p} E_{w} \sigma T_{0}^{4} F_{p}
$$

where,

$$
\begin{aligned}
F_{p}= & \frac{Z}{2 \pi}\left[\int_{-G_{i}}^{0} \int_{0}^{\pi}\left\{\left(1-R_{1} \cos \psi\right)\left(G^{2}+Z Z_{a}\right)^{-1.5}\right\}\right. \\
& \times d \psi d G+\int_{0}^{1} \int_{0}^{\pi}\left\{\left(1-R_{1} \cos \psi\right)(b G+1)^{4}\right. \\
& \left.\left.\times\left(G^{2}+Z Z_{a}\right)^{-1.5}\right\} d \psi d G\right] \ldots \ldots \ldots \ldots \ldots \ldots . . .(A-4) \\
Z= & \left\{D /\left(2 X_{b}\right)\right\}^{2} \\
R_{1}= & 2 r / D \\
Z_{a}= & 1+R_{1}^{2}-2 R_{1} \cos \psi \\
G & =X / X_{b} \\
G_{i} & =X_{i} / X_{b} \\
b & =\left(T_{r} / T_{0}\right)-1
\end{aligned}
$$

$X_{i}$ : the length of blowpipe upstream of the injection point effective to the radiation

$F_{p}$ is a modified view factor and depends not only on the blowpipe geometry but also on the value of $\left(T_{r}\right)$ $\left.T_{0}\right)$. The variation of $F_{p}$ with the dimensionless pipe length, $X_{b} / D$ is shown in Fig. A-2. Since the effect of $R_{1}$ on $F_{p}$ is very small, the value of $F_{p}$ at $R_{1}=0$ (the case that a particle is on the axis of blowpipe) is assumed. Then,

$$
\begin{aligned}
F_{p}= & \frac{b^{4} Z}{4}\left\{\frac{1+3 Z}{(1+Z)^{1 / 2}}+3 Z \ln \frac{Z^{1 / 2}}{1+(1+Z)^{1 / 2}}\right\} \\
& +\frac{2 b^{3} Z}{(1+Z)^{1 / 2}}-3 b^{2} Z\left\{(1+Z)^{-1 / 2}\right. \\
& \left.+\ln \frac{Z^{1 / 2}}{1+(1+Z)^{1 / 2}}\right\}+2 b\left\{Z^{1 / 2}-\frac{Z}{(1+Z)^{1 / 2}}\right\} \\
& +0.5\left\{(1+Z)^{-1 / 2}-\frac{G_{i}}{\left(G_{i}^{2}+Z\right)^{1 / 2}}\right\} \ldots \ldots \ldots \ldots .
\end{aligned}
$$

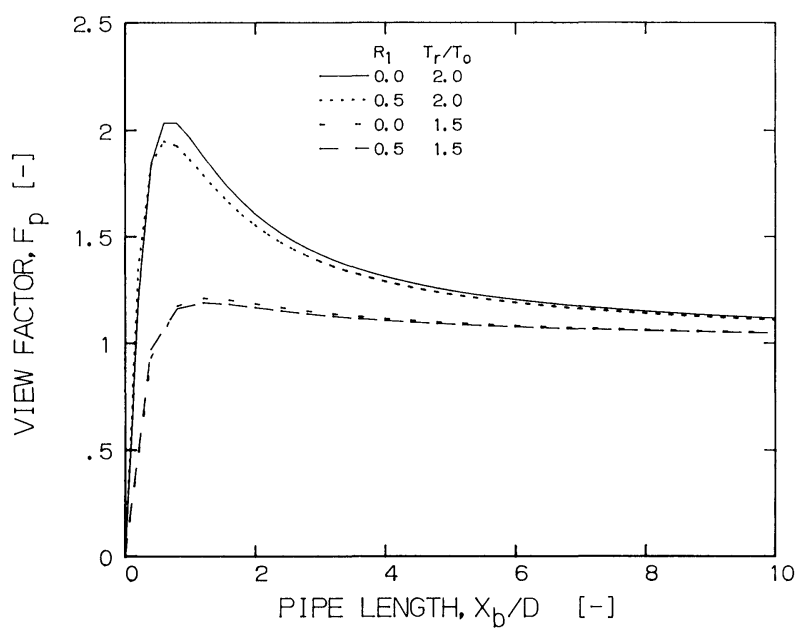

Fig. A-2. Modified view factor in relation to dimensionless pipe length.
Additionally, when the values of $X_{b}$ and $X_{i}$ become greater, the value of $F_{p}$ is converged to unity for a given $b$.

\section{Appendix B}

When coal particles are exposed to a hot air, the evolution of volatile matter takes place from the particle surface. The rate of the evolution can be expressed by the following formula.

$$
M_{0}\left(-\frac{d V}{d t}\right)=\pi D_{p 0}^{2} A_{\mathrm{o}} V \exp \left(-\frac{E}{R T_{s}}\right)
$$

where, $V:$ the volatile matter content at time $t$

$A_{o}:$ the frequency factor

$E:$ the activation energy

$R$ : the gas constant.

It is assumed that the volatile matter is oxidized as soon as it is evolved from the particle surface and the resultant heat of oxidation contributes to the temperature rise of the particle. Then, a heat balance around the particle in place of Eq. (9) is given by,

$$
\begin{aligned}
\frac{d T_{s}}{d t}= & A_{1}\left\{h\left(T_{g}-T_{s}\right)+G_{m}\right. \\
& \left.+Q_{v} A_{0} V \exp \left(-\frac{E}{R T_{s}}\right)\right\}
\end{aligned}
$$

where, $Q_{v}$ : the heat of oxidation per unit mass of volatile matter.

Next, in the warm-up zone, the equation of continuity, the ideal gas law and a heat balance of the gas phase are represented by,

$$
\begin{aligned}
\rho V_{a}=\rho_{0} V_{a 0} \quad & \text { (continuity) } \\
T_{g} \rho=T_{0} \rho_{0} \quad & \text { (ideal gas law) } \\
\frac{d}{d X}\left(\rho V_{a} C_{\hat{p}} T_{g}\right)= & \left(\frac{\mathcal{N}}{V_{p}}\right) \pi D_{p 0}^{2} h\left(T_{s}-T_{g}\right) \\
& \text { (heat balance) }
\end{aligned}
$$

or

$$
\frac{d T_{g}}{d t}=A_{2} h\left(T_{s}-T_{g}\right)
$$

where, $A_{2}=\mathcal{N} \pi D_{p 0}^{2} /\left(\rho_{0} V_{a 0} C_{p}\right)$.

Equations (2) to (4) and (B-1) to (B-5) are solved numerically with respect to time $t$ and give the length of the warm up zone, $X_{p}$ at which the temperature of the particle, $T_{s}$ becomes the ignition temperature, $T_{i g}$. The numerical computations use the following initial conditions (at $t=0$ and $X=0$ ),

$$
\begin{aligned}
& T_{s}=T_{s 0}=298 \mathrm{~K}, \quad T_{g}=T_{0}=1200 \mathrm{~K}, \\
& V_{p}=V_{p 0}=0, \quad V_{a}=V_{a 0}, \quad \rho=\rho_{0}, \quad V=0.3
\end{aligned}
$$

and the following constant values of $A_{o}$ and $E$ which have been reported by Kobayashi ${ }^{11}$ for bituminuos coal of $60 \times 10^{-6} \mathrm{~m}$ in diameter,

$$
\begin{aligned}
& 6 A_{o} /\left(D_{p 0} \rho_{s}\right)=6.6 \times 10^{4} \mathrm{~s}^{-1} \\
& A_{o}=792 \mathrm{~kg} / \mathrm{m}^{2} \mathrm{~s}, \quad E=1.046 \times 10^{5} \mathrm{~J} / \mathrm{mol} .
\end{aligned}
$$

From Fig. B-1, it is said that the variation of $T_{g}$ with the distance, $X$ is very small (assumption (6)) 


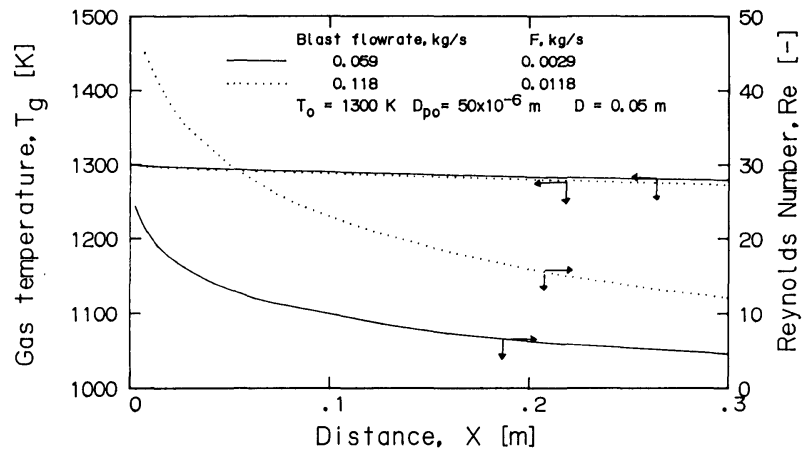

Fig. B-1. Gas temperature and Reynolds number along the $X$-direction in the warm-up zone.

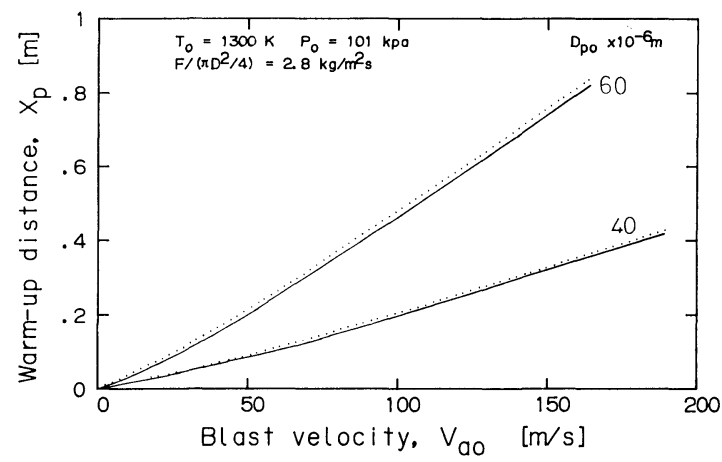

Fig. B-2. Warm-up zone distance in relation to blast velocity.

and that the value of $R e$ is in the Allen region $(2<$ $R e<500$ ) (assumption (7)).

Figure B-2 shows the length of the warm up zone, $X_{p}$ in relation to the blast velocity, $V_{a 0}$ where the full line is the approximate one and the dotted line is the numerical one. From this comparison, the effect of volatile matter on the length of the warm-up zone seems to be very small (assusption (5)).

\section{Appendix C}

Assumptions (8) and (9) are examined by the numerical solution derived below. In order to calculate the variation of pressure, $P$ along $X$-direction, the equation of motion is also used.

$$
-\frac{d}{d X}\left(\rho V_{a} V_{a}\right)-\frac{d\left(P G_{c}\right)}{d X}-\frac{4}{D} F_{r}=0
$$

The first term in Eq. (C-1) is the momentum flux per unit cross sectional area and the second term is the pressure force. Fanning's equation is used to determine $F_{r}$, the friction force acting on the inside wall,

$$
F_{r}=f\left(\rho V_{a}^{2} / 2\right)
$$

where, $f=0.0791 / R e^{\prime 0.25} \quad\left(2.1 \times 10^{3}<R e^{\prime}<10^{5}\right)$

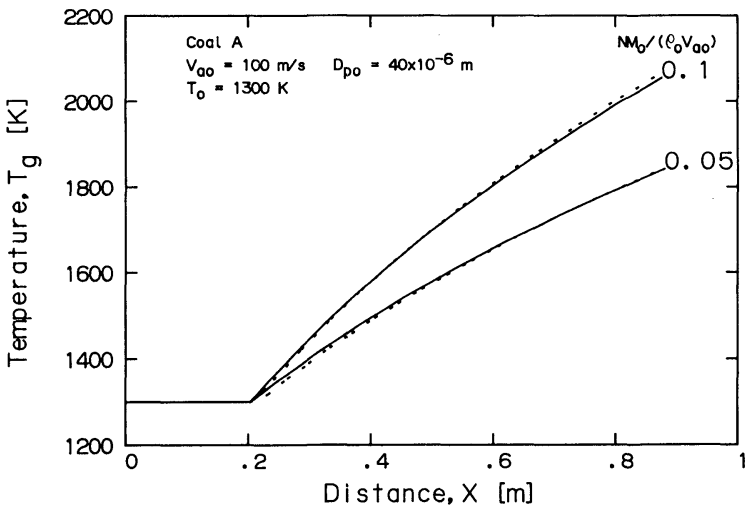

Fig. G-1. Blast gas temperature along the $X$-direction in the burning zone.

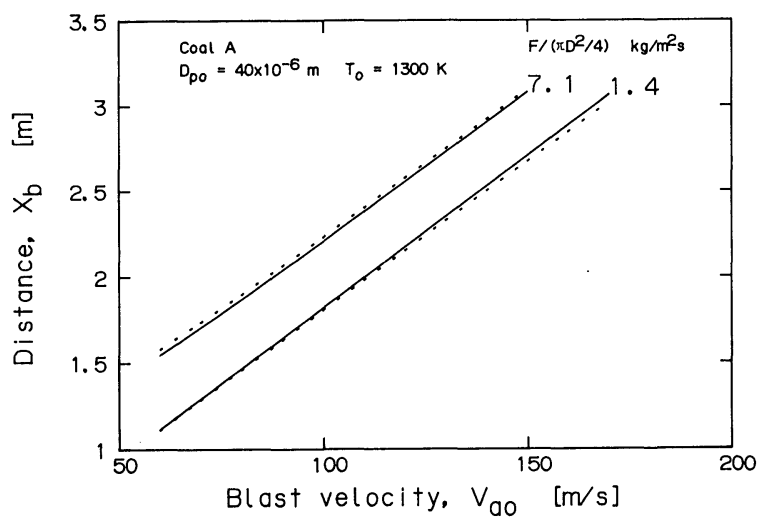

Fig. C-2. Distance between injection position and position where particles burn out in relation to blast velocity.

$$
R e^{\prime}=\rho D V_{a} / \mu .
$$

Therefore, the simultaneous solution of Eqs. (2) to (4), (11) to (13) and (G-1) gives the variation of $V_{a}$, $T_{g}$ and the other factors such as $P$ and $U$ with the distance, $X$. The initial conditions $\left(t=t_{1}\right.$ or $\left.\theta=0\right)$ are:

$$
\begin{aligned}
& V_{a}=V_{a 0}, \rho=\rho_{0}, M_{d}(\theta)=1, P=P_{0}, \\
& V_{p}=V_{p}\left(t_{1}\right), X=X_{p}\left(t_{1}\right), T_{g}=T_{0}
\end{aligned}
$$

The numerical results are compared with those calculated from Eqs. (15) and (16). Figures G-1 and G-2 show the variation of $T_{g}$ with the distance, $X$ and the warm-up plus burning zone distance, $X_{b}$ with $V_{a 0}$, respectively. The numerical results are given by the dotted line and the approximate ones are the full line. In this numerical calculation, the variation of $P / P_{0}$ with $X$ has been in the range 0.99 to 1 and that of $U / V_{a 0}$ has been between 0 and 0.1 in the burning zone. Consequently, assumptions (8) and (9) and the approximate solutions given by Eqs. (14) to $(16)$ are considered to be reasonable. 